\title{
Learning French through English: students' beliefs and motivations and the role of English as language medium
}

\author{
Ladislav Václavík
}

\begin{abstract}
English has become a language commonly used in fields such as business, diplomacy, or tourism. It is also a medium which enables the transfer of knowledge and the development of ideas in science and education. Scientists and undergraduates can nowadays pursue their research and studies at laboratories and universities all over the world using English as the language of the educational process. Thus, they access knowledge in their respective fields through English, and this also applies to learning other languages. Learning a foreign language using English poses various challenges, starting from the learners' level of English over to the influences that English can have on the process of acquisition. Also, learners can have beliefs about learning the other language (L3), which differ from beliefs they have about learning English. This set of ideas, attitudes and opinions could have an impact on how students learn L3. This paper explores the beliefs about, and motivations for, language learning among a small group of Erasmus students in the International Relations Programme. The students, who have various ethnic origins and language backgrounds, took part in a thirteen-week course of French for Beginners, taught in English by a Czech teacher. Most students were complete beginners, but others already had a basic knowledge of French, as the entry questionnaire had shown. This course of French for specific purposes (diplomacy) covered the first three units of an A1-A2 textbook called Objectif Diplomatie: Le français des relations européennes et internationales. At the end of the course, learners completed a questionnaire in English. This research gauges the role of English as a medium in learning French at a beginner's level and investigates students' perceptions of the accuracy and the difficulty of learning French through English. The study avoids any generalisations. It reports group-specific results intending to show whether, and to what extent, students conform to other research findings in the areas of learner beliefs and motivations in English-medium language instruction.
\end{abstract}

\section{Introduction}

The present paper reports on the findings of a study which examined Erasmus university students' beliefs about language learning with the help of an adapted version of a popular self-administered questionnaire, namely Horwitz's (1987) Beliefs About Language Learning Inventory (BALLI). Although numerous BALLIbased studies have been carried out in the past (Mantle-Bromley, 1995; Cortazzi, \& Jin, 1996; McCarger, 1999; Horwitz, 1999; Mori, 1999; Sakui, \& Gaines, 1999; Yang, 1992; Yang 1999; Siebert, 2003; Tercanlioglu, 2005; Nikitina, \& Furuoka, 2006; Bernat, \& Lloyd, 2007), the present study is unique because rather than discussing the effects of contexts (culture, achievement level, major subjects, or gender) on students' beliefs about language learning, it compares students' be- 
liefs about learning two different languages. Furthermore, it examines the role of English in learning French as perceived by learners themselves.

After a brief outline of previous studies on beliefs about language learning, this paper will describe the method, analyse the results of the survey, and interpret the data. Given the limited number of participants, the current study does not present any results that would pretend to be statistically significant but rather delineates how students' beliefs differed concerning the respective languages and how English, as a medium language, impacted on students' learning French.

\section{Literature review - Beliefs about language learning}

Learners' beliefs about language learning have been recognised as an essential part of the learning process, alongside many other individual differences in language learning (Dörnyei, 2005; Horwitz, 1999; Wenden, 1999). Horwitz (1987: 120) defines beliefs as "opinions on a variety of issues and controversies related to language learning". Wenden (1999: 435) considers beliefs to be "learners' acquired knowledge about learning: the nature of learning, the learning process, and humans as learners, including themselves".

Learners' beliefs have been linked with other learner variables, such as language learning strategies (Horwitz, 1987, 1988) or foreign language anxiety (Horwitz, 1988; Truitt, 1995). Hence, studying students' beliefs about language learning is of major importance as they can, for example, affect learner motivation to acquire the target language; thus, unrealistic beliefs concerning the time required to achieve proficiency might lead to frustration (Cohen and Dörnyei, 2002). At the same time, students' beliefs are not a priori and can be influenced by learners' previous experiences as well as cultural background (Horwitz, 1987).

Since Horwitz constructed her BALLI questionnaire (1987), many researchers have explored language learning beliefs among various learner groups and contexts. Horwitz herself $(1987,1988)$ studied foreign language learners' beliefs about learning English as a foreign or second language in the US. Other studies have covered learners' beliefs worldwide, mainly in East Asia (e.g. Bernat, 2004; Diab, 2006; Nikitina and Furuoka, 2006; Peacock, 1999; Riley, 2009; Sakui \& Gaies, 1999; Tanaka \& Ellis, 2003; Yang, 1999). Meanwhile, Turkish students were also examined (Altan, 2006; Tercanlioglu, 2005). This study contributes to this research by bringing the tool to the Czech Republic, analysing international students' beliefs about learning L3 through English. Cultural background, as some studies understandably suggest, could play an important role in the development of an individual's beliefs about language learning (e.g. Diab, 2006; Horwitz, 1999; Wenden, 1999). At the same time, Fugiwara (2014) claims that in many studies that examined belief variations, the participants were different in some important 
aspects, such as participants' age, stage of language learning (e.g. beginner level or advanced level), professional status, and the target language. Given these discrepancies among the learners, Fugiwara warns that it is almost impossible to identify whether the participants' cultural backgrounds were attributable to the variations of language learning beliefs.

The BALLI has been the most widely used measurement tool; however, some issues were raised concerning the validity of the instrument (Kuntz, 1996; Nikitina \& Furuoka, 2006). One of the most crucial criticisms concerns the structure of the questionnaire itself and the statistical relevance one can deduct from the results obtained. The original BALLI contained 34 questions divided into five categories to be measured. This category grouping, however, cannot be empirically verified through statistical analyses (Kuntz, 1996). Fujiwara (2011) points out further that it is not yet clear whether the language learning beliefs have a multidimensional structure covering the five themes proposed by Horwitz (1987). As Fujiwara notes (2014), in most BALLI studies, the descriptive data (i.e. the frequencies of the response options, e.g. "strongly agree", "agree") have been used to compare groups of learners, without appropriate statistical analyses. Only in some cases (e.g. Bernat \& Lloyd, 2007; Peacock, 2001; Rifkin, 2000; Schulz, 2001; Shah et al., 2009), inferential statistical analyses were conducted, and the mean scores were compared. The statistical validity remains unknown when the comparison is made at single item levels.

Sage (2011) examined the issue of analysing data only at single-item levels. This practice is still noticeable even in recent BALLI studies (e.g. Altan, 2006; Bernat, 2004; Tercanlioglu, 2005); however, it was judged problematic in terms of its measurement validity. Sage argued that the BALLI studies are limited in their validity due to this practice of analysis, as the single item reliabilities are statistically deficient by nature. Given these methodological constraints, we can agree with Horwitz (1999) and admit that "clear-cut conclusions do not seem possible" (p. 574), despite many variations and similarities across several groups of learners that could otherwise be identified.

Despite the criticism, this study follows Horwitz' original distribution and regroups the items into five areas devised by its inventor. This decision was motivated by the fact that the number of participants in the study does not allow for any statistically significant processing, thus rendering advanced techniques, such as factor analysis, inappropriate.

Horwitz categorised the 34 BALLI items into the following five themes: (a) foreign language aptitude (9 items); (b) the difficulty of language learning (6 items); (c) the nature of language learning (6 items); (d) learning and communication strategies (8 items); and (e) motivation and expectations (5 items). Only a few studies (Nikitina \& Furuoka, 2006; Truitt, 1995; Yang, 1999) examined empirically - using 
factor analysis - whether the items within the BALLI themes measure the same subcategory of the construct. Similar reconsiderations of the original distribution are to be found in other studies as well (Peacock, 2001; Rifkin, 2000; Schulz, 2001). Our research, as mentioned above, abstains from such re-examination.

To our best knowledge, Diab's study (2005) is the only one to have investigated and compared students' beliefs about learning English and French. Examining students' beliefs in the Lebanese context, Diab found that her participants held a variety of beliefs, many of which related to the political and socio-cultural context of foreign language education in Lebanon. In her study, English - unlike French - was considered an easy language. Also, students seemed to have strong motivational incentives for learning English and agreed that it is more important to learn English than French. Diab, however, did not consider the role of English in learning French as perceived by learners. While covering similar ground as Diab, the current article addresses this deficiency with a view of implementing the results into teaching practice.

\section{Method}

This study aimed to investigate the variations of the beliefs about language learning held by a group of university students on Erasmus at a major Czech tertiaryeducation institution through descriptive statistical analysis of their responses to BALLI. The beliefs examined in this study are measured by a modified version of BALLI, covering four theoretical areas proposed by Horwitz (1987). Furthermore, the study analyses the role of English in the learning process as perceived by learners.

The following research questions were addressed.

1. What are students' beliefs about learning French as compared to their beliefs about learning English?

2. What are students' beliefs about learning French through English?

3. Was using English an asset or a liability in learning French?

The last research question could be considered as a subcategory of the second one, however, keeping it apart allows for a clearer view of how important English was as a medium language compared to using the mother tongue or French itself. Also, answering the question can have significant consequences in terms of modifications in teaching methodology, adaptation of teaching style and implementation of more immersive teaching techniques. 


\subsection{Participants}

The participants in this study were foreign undergraduate students $(\mathrm{N}=15)$ in a large state university in the Czech Republic. The students studied in the English programme at the Faculty of Social Sciences. The programme, called International Relations, is taught entirely in English and is aimed at Erasmus students coming from different language and cultural backgrounds. In the group analysed, the following countries were represented: Azerbaijan (1 student), Bosnia and Herzegovina (1), Egypt (1), Finland (1), Kenya (1), Malaysia (1), Mozambique (1), Philippines (1), Slovakia (3), Sri Lanka (1), United Arab Emirates (1), and the USA (2). The students were in their first year of studies, and their age ranged from 19 to 22.

\subsection{Instrument}

A modified version of the BALLI (Beliefs about language learning inventory) was used to measure language learning beliefs (see Attachment). Given the purpose of the present study, the original 34-item questionnaire was rebuilt so that it included two analogical sets of items corresponding to learning French and English. These sets were then complemented by another 13 items that related to the role of English in learning French. In the self-administered questionnaire, the participants were asked to indicate to what extent they agree or disagree with statements on a five-point Likert scale ranging from strongly disagree (1) to strongly agree (5). The questionnaire is divided into four parts. Parts I-IV included questions gauging students' beliefs about learning English, French or foreign languages in general, as well as about the role of English in learning French.

The participants' responses to the 46 items were analysed using descriptive statistics. Given this fact, the results of the inventory generated from the items cannot be called factors in a statistical sense, as they were not the actual results of factor analysis. However, the current study acknowledges its limitations and examines the individual items following four major areas based on Horwitz, namely difficulty of language learning (Items 7, 8, 31, 32); the nature of language learning (Items 11, 23, 24, 35); and learning and communication strategies (Items 29, 30, $33,34,36,37$ ) and motivation (Items 26, 28, 38, 39). To these areas covered in two sets comparing English and French, the study adds items tracing the role of English as a medium language in learning French (Items 16, 17, 18, 19, 20, 21, 40, $41,42,43,44,45,46)$.

\subsection{Method of data analysis}

Given the restricted number of participants, descriptive statistics were used to present the data. The tables shown in the study represent the number of students 
who strongly disagree or disagree, those who are neutral in their answer, and the number of students agreeing (or strongly agreeing) with the statements. Also, the mean scores are provided, as these allow for a clearer comparison between the two sets of data.

Data were collected from participants in June 2019. The questionnaire was administered by the researcher at the end of the last seminar in that term. Before the BALLI was handed out, the researcher briefly described the nature and aim of the study, assuring the participants that the data provided would be kept in strict anonymity.

Despite the criticism mentioned above, the original version of the BALLI has been used over the past thirty years, which ensures fair validity through repeated administration. At the same time, the present study acknowledges its limitations and discusses them below.

\section{Results and discussion}

In the sample, there were six female and nine male students. For three students, English was the native language. The following table shows the results concerning the first area, namely the difficulty of language learning. As can be seen, English is perceived as a relatively easy language to acquire, unlike French, which corresponds with the findings provided by Diab (2004). Furthermore, students believe that acquiring active French language skills is more complicated than mastering active language skills in English. This confirms the well-known fact that the active skills of a language are vital in determining the relative difficulty of learning a foreign language.

Tab. 1: Factor 1 - Difficulty of language learning (English); * SD/D = strongly disagree/disagree; $N=$ neutral; $A / S A=$ agree, strongly agree

\begin{tabular}{|l|c|c|c|c|}
\hline & SD/D* & $\mathrm{N}$ & $\mathrm{A} / \mathrm{SA}$ & $\mathrm{M}$ \\
\hline $\begin{array}{l}\text { 7 English is easier to read and understand } \\
\text { than write and speak }\end{array}$ & 12 & 3 & 0 & 1.5 \\
\hline 8 English is an easy language & 0 & 6 & 9 & 3.9 \\
\hline
\end{tabular}

Tab. 2: Factor 1 - Difficulty of language learning (French)

\begin{tabular}{|l|c|c|c|c|}
\hline & SD/D & N & A/SA & M \\
\hline $\begin{array}{l}\text { 31 French is easier to read and understand } \\
\text { than write and speak }\end{array}$ & 3 & 2 & 10 & 3.9 \\
\hline 32 French is an easy language & 5 & 7 & 3 & 2.8 \\
\hline
\end{tabular}

As far as the nature of language learning is concerned, students in the sample believe that learning a foreign language is mostly a matter of learning new vocabulary rather than grammar rules. The study does not expect there to be any 
differences between learning English and learning French; hence no comparison is provided. This finding, however, could be used in teaching where more emphasis could be placed on learning new vocabulary to enhance students' impression that they are learning a language, thus strengthening the motivation, and boosting the progress.

Tab. 3: Factor 2 - Nature of language learning

\begin{tabular}{|l|c|c|c|c|}
\hline & SD/D & N & A/SA & M \\
\hline 23 Vocabulary & 2 & 2 & 11 & 3.9 \\
\hline 24 Grammar & 2 & 7 & 6 & 3.2 \\
\hline
\end{tabular}

It proved illuminating to include an item asking students about the role of culture in learning the respective languages. As the following table shows, it turned out that students do not consider it necessary to learn about English-speaking cultures when speaking English. The French language, on the contrary, seems to have kept a more vital link to its subjacent culture. This could also be related to the international character of English, which has led to weakened national/cultural footing.

Tab. 4: Factor 2 - Nature of language learning (role of culture)

\begin{tabular}{|l|c|c|c|c|}
\hline & SD/D & N & A/SA & M \\
\hline 11 English & 10 & 2 & 3 & 2.3 \\
\hline 35 French & 2 & 7 & 6 & 3.3 \\
\hline
\end{tabular}

In the third area, namely learning and communication strategies, learners have expressed strong beliefs about correct pronunciation and accuracy in speaking French. As the following table shows, students seem well-aware of the importance of correct pronunciation when speaking French. Curiously, they do not think that bad pronunciation should stop them from using French.

Tab. 5: Factor 3-Common learning and communication strategies (French)

\begin{tabular}{|l|r|r|r|c|}
\hline & SD/D & N & A/SA & M \\
\hline 29 enjoy practising with natives & 2 & 7 & 6 & 3.4 \\
\hline 30 feel timid & 2 & 6 & 7 & 3.7 \\
\hline 33 excellent pronunciation important & 0 & 4 & 11 & 4.3 \\
\hline 34 ok to guess & 4 & 5 & 6 & 3.2 \\
\hline 36 early errors difficult to correct later & 8 & 3 & 4 & 2.7 \\
\hline 37 speak French only correctly & 14 & 0 & 1 & 1.7 \\
\hline
\end{tabular}

When compared, students' beliefs concerning the respective languages show some significant differences (see Tab. 6). Some items show only minor divergence students believe, for example, that it is ok to guess if they do not know a word 
in the respective language. Similarly, students deem that making early errors in English or French does not impede their correction later. Furthermore, accuracy in speaking does not seem to play any crucial role in either language. On the contrary, there are areas where speaking English or French does interfere: speaking French makes students feel timider than speaking English, probably due to the difficulty in pronunciation. At the same time, mastering excellent pronunciation seems to be more vital for French than English. Again, this seems logical given the relative difficulty of prescriptive, normative French phonetics, especially when compared to the descriptive character of English.

Tab. 6: Factor 3 - Common learning and communication strategies (English vs French)

\begin{tabular}{|l|c|c|}
\hline & Mean - English & Mean - French \\
\hline 5, 29 enjoy practising with natives & 4.0 & 3.4 \\
\hline 6, 30 feel timid & 1.8 & 3.7 \\
\hline 9, 33 excellent pronunciation important & 3.3 & 4.3 \\
\hline 10, 34 ok to guess & 3.6 & 3.2 \\
\hline 12, 36 early errors difficult to correct later & 2.3 & 2.7 \\
\hline 25, 37 speak only correctly & 1.2 & 1.7 \\
\hline
\end{tabular}

As for the area of motivation (see Tab. 7), students believe that knowing French has got some importance, as none of them disagreed with the question entirely. However, the importance is relatively moderate in their view, as reflected in Item 39, which asked learners whether it is important to speak French for them as students on Erasmus in the Czech Republic. Similarly, students do not seem to be envisaging working in a French-speaking environment in the future, which points out at non-pragmatic motivation in learning French. When asked further about the reasons for learning French, 35\% stated career reasons, 19\% opted for social reasons, $27 \%$ mentioned communication with foreign entities. Interestingly, $16 \%$ learn French because it is considered a universal/international language, while 3\% do not consider learning French necessary.

Tab. 7: Factor 4-Motivation (French)

\begin{tabular}{|l|r|r|r|c|}
\hline & SD/D & N & A/SA & M \\
\hline 26 it is important to know French & 0 & 8 & 7 & 3.8 \\
\hline 28 I would like to get to know native speakers & 0 & 3 & 12 & 4.4 \\
\hline 38 work in a French-speaking environment & 6 & 5 & 4 & 2.9 \\
\hline 39 French in Czech Republic & 14 & 0 & 1 & 1.3 \\
\hline
\end{tabular}

When compared to reasons leading students to learn English, some interesting differences appear. Curiously, only 27\% learn English for career reasons, as opposed to $35 \%$ in the case of French. For English, social reasons (26\%) and the international character of the language (25\%) seem to play a more important role as motivators. If compared further, the motivation factor provides more illuminating 
differences (see Tab. 8). Generally, students believe that learning English is more important than learning French, which is partly reflected in the fact that French is considered unimportant in everyday situations that students face in the Czech Republic (Items 15, 39). Students also differ significantly in their beliefs about working in an environment where the respective language is spoken. At the same time, students are similarly interested in encountering native speakers.

Tab. 8: Factor 4 - Motivation (English vs French)

\begin{tabular}{|l|c|c|}
\hline & Mean - English & Mean - French \\
\hline 2, 26 it is important to know English/French & 5.0 & 3.8 \\
\hline 4, 28 I would like to get to know native speakers & 3.9 & 4.4 \\
\hline 13, 38 work in an English/French-speaking environment & 4.6 & 2.9 \\
\hline 15, 39 English/French in the Czech Republic & 4.5 & 1.3 \\
\hline
\end{tabular}

The last part of the questionnaire concerned students' beliefs about the role of English in learning French (see Tab.9). The results show that students were quite aware of the similarities between the two languages. This issue could be explored in more detail in the future, and the results of the survey could also be implemented into the teaching process where similarities between the French and English vocabulary of diplomacy and international relations (students' study programme) could be further stressed and explained. Translation from English into French, however, is not, according to the participants, homologous to learning languages as such (Item 44). At the same time, translation seemed to play a considerable role in learning French, as only a small percentage of the learners used monolingual dictionaries in the process. This, however, is quite understandable, given the beginner's level. Translating seems to have been done mainly between French and English, as students seem to have avoided their respective native tongues when learning French, preferring English (Item 20). The tendency to avoid one's native language can be ascribed to the fact that English was the medium-language throughout the course.

Tab. 9: Learning French through English

\begin{tabular}{|l|r|r|r|c|}
\hline & SD/D & N & A/SA & M \\
\hline 19 I was aware of the similarities between French and English & 3 & 0 & 12 & 4.1 \\
\hline 20 English rather than native language & 0 & 2 & 13 & 4.5 \\
\hline 21 translation from French into NT & 10 & 3 & 2 & 2.1 \\
\hline 42 translation from English into NT & 14 & 1 & 0 & 1.3 \\
\hline 44 learning French = translation from English into French & 5 & 5 & 5 & 3.0 \\
\hline 46 I used a French-only dictionary & 10 & 3 & 2 & 2.0 \\
\hline
\end{tabular}

When it comes to the last research question, English seems to have been an asset rather than a liability (see Tab. 10). Students have noticed similarities mainly in vocabulary, as French and English share a considerable amount of words of 
Latin and Greek origin, which, at the same time, are quite common in diplomacy and international relations. According to students' estimate, it was not difficult to study French using English, nor was the teacher's use of English an obstacle. It is also interesting to see that students preferred the teacher to speak English rather than use French only. Further analysis, such as semi-structured interviews, could provide a more detailed justification of this belief. It can only be speculated whether students view immersive teaching practices as impediments to making quick progress.

Tab. 10: English as an asset or a liability

\begin{tabular}{|c|c|c|c|c|}
\hline & $\mathrm{SD} / \mathrm{D}$ & $\mathrm{N}$ & $\mathrm{A} / \mathrm{SA}$ & M \\
\hline 16 the knowledge of English was beneficial in learning French vocabulary. & 1 & 0 & 14 & 4.5 \\
\hline 17 the knowledge of English was beneficial in learning French grammar. & 4 & 3 & 8 & 3.5 \\
\hline 18 the knowledge of English was beneficial in learning French pronunciation. & 9 & 6 & 0 & 1.9 \\
\hline 40 It was hard for me to study French using English. & 14 & 1 & 0 & 1.3 \\
\hline 41 I would prefer if the teacher spoke only French. & 12 & 0 & 3 & 1.9 \\
\hline 45 In class, I had problems understanding the teacher's English & 15 & 0 & 0 & 1.0 \\
\hline
\end{tabular}

\section{Conclusion and limitations}

The present study tried to provide answers to three research questions concerning students' beliefs about learning French and English, about learning French through English and about the role of English in learning French. At the same time, the study attempted to compare students' beliefs about learning the respective languages.

The results show that students in this specific group feel timid when learning French, as opposed to learning English. The Romance language also seems to be more difficult for students to master. Another significant difference concerned students' expectations in the professional area, as they show less enthusiasm to work in a French-speaking environment than in the English-speaking one. At the same time, French maintains a strong attachment to its cultural heritage and background, which seems to play an essential role as a motivational component of the learning process. The role of culture in motivation, however, was not addressed directly in the present study.

As for the beliefs about learning French through English, students rely heavily on English and use it more often than their native languages, both in the learning process and in translation. Translation, even if not identified with learning, still plays a vital role as only a minority of students used a monolingual dictionary when confronted with an unknown word. 
Finally, English was not considered as a liability in the teaching and learning processes, as students were aware of similarities between the languages and teacher's use of English did not impede the teaching. Students also expressed satisfaction with the fact that the teacher did not use only French in the class and relied on English as a medium-language.

There are two major limitations of the present study. Firstly, the limited number of participants does not allow for any significant generalisations, as the results cannot be processed statistically. This, however, does not make the findings irrelevant for the specific context in which the study originated. Secondly, the methodology might have been tailored to the group, and the results triangulated using a complementary survey method, such as an interview or students' logbooks. Thus, the results could have been sustained by other data sources, and the findings could have been more detailed and complex. Qualitative data might thus have shed light on specific issues and allow the researcher to establish causal links where none could have been achieved using quantitative methodology. For instance, the issue of timidity could have been tackled in an interview and possible links to linguistic or social factors established. This knowledge could further facilitate the teaching task consisting of unblocking possible feelings of shyness or false assumptions about learning or speaking French.

Despite these shortcomings, the study provided important and relevant data, and the findings can be implemented in the future teaching process. Some results stem from the linguistic nature of English and French. Thus, given the importance students attribute to pronunciation and vocabulary, more practice can be provided in these two areas. What is more, students' awareness of similarities in the latter area can be exploited in a series of exercises where analogical sets of English-French words can be presented and learned together. Other findings are of psychological and social importance. For instance, the study showed that students feel timid when speaking French. This hindrance can be addressed directly in classes by promoting a relaxed and non-inhibitory atmosphere and an encouraging attitude from the teacher. Another set of factors relates to the nature of learning the language. Here, students can be encouraged, for instance, to use monolingual dictionaries from the very start. This practice could be fostered by immersive teaching methodology in which French, rather than English, would be used throughout the whole class, either from the very start or implemented gradually.

The study has corroborated some of the previous findings concerning students' beliefs about learning French (Diab, 2005), bringing the tool to a different sociocultural environment. Unlike previous studies, the participants of the present study were all international students. This factor could be further explored in the future, and the role of different cultural and linguistic backgrounds analysed. 
Also, the role of English as a medium in learning French (or other languages) deserves a more detailed look. Future research could thus focus on similarities between using English to teach different languages (e.g. French or German) and the implementation of the results into the teaching practice. In this way, students could be made aware of common mistakes, false friends or efficient strategies which could facilitate the complex process of learning French or other languages through English.

\section{References}

ABDi, H., \& BAHAREH, A. (2015). A synopsis of researches on teachers' and students' beliefs about language learning. International Journal on Studies in English Language and Literature (IJSELL), 3(4), 104-114.

Altan, M. Z. (2006). Beliefs about language learning of foreign language-major university students. Australian Journal of Teacher Education, 31(2), 45-52. Retrieved from http://ro.ecu.edu.au/cgi/ viewcontent.cgi?article $=1316 \&$ context $=$ ajte

BERNAT, E., \& LLOYD, R. (2007). Exploring the gender effect on EFL learners' beliefs about language learning. Australian Journal of Educational and Developmental Psychology (7), 79-91.

CoHEn, A. D., DöRnYeI, Z. (2002). Focus on the language learner: motivation, styles, and strategies. In Schmitт, N. (Ed.), An Introduction to Applied Linguistics, pp. 170-190. London, Arnold.

DiAB, R. L. (2005). University students' beliefs about learning English and French in Lebanon. System 34, 80-96.

DÖRNYEI, Z. (2005). The psychology of the language learner: Individual differences in second language acquisition. Mahwah, NJ: Lawrence Erlbaum Associates.

FUGIWARA, T. (2011). Language learning beliefs of Thai EFL university students: dimensional structure and cultural variations. Electronic Journal of Foreign Language Teaching, 8(1), 87-107.

FUGIWARA, T. (2014). Language learning beliefs of Thai EFL university students: variations related to achievement levels and subject majors. Electronic Journal of Foreign Language Teaching, 11(2), 300-311.

HoRwitz, E. K. (1987). Surveying student beliefs about language learning. In A. WENDEN, \& J. RUBIN (Eds.), Learner strategies in language learning, pp. 119-129. Englewood Cliffs, NJ: Prentice-Hall.

HoRwiTz, E. K. (1988). The beliefs about language learning of beginning university foreign language students. The Modern Language Journal, 72(3), 283-294.

HoRwitz, E. K. (1999). Cultural and situational influences on foreign language learners' beliefs about language learning: A review of BALLI studies. System, 27, 557-576.

Kuntz, P. (1996). Students of 'easy' languages: Their beliefs about language learning. (ERIC document reproduction service No. ED 397658)

Mantle-Bromley, C. (1995). Positive attitudes and realistic beliefs: Links to proficiency. Modern Language Journal, 79(3), 372-386.

NikitinA, L., \& FuRUoKA, F. (2006). Re-examination of Horwitz's Beliefs About Language Learning Inventory (BALLI) in the Malaysian context. Electronic Journal of Foreign Language Teaching, 3(2), 209-219. Retrieved from http://e-flt.nus.edu.sg/v3n22006/nikitina.pdf

PEAcock, M. (1999). Beliefs about language learning and their relationship to proficiency. International Journal of Applied Linguistics, 9(2), 247-265. 
PEACOCK, M. (2001). Pre-service ESL teachers' beliefs about second language learning: a longitudinal study. Systems, 29(2), 177-195.

RIEGER, B. (2009). Hungarian University Students' Beliefs about Language Learning: A Questionnaire Study. WoPaLP (3), 97-113.

RIFKIN, B. (2000). Revisiting beliefs about foreign language learning. Foreign Language Annals, 33(4), 394-408.

RILEY, P. A. (2009). Shifts in beliefs about second language learning. RELC Journal, 40(1), 102-124.

SAGE, C. M. (2011). Learner beliefs in South Korea: Enriching the description. Electronic Journal of Foreign Language Teaching, 8(2), 216-233.

SAKUI, K., \& GAIES, S. J. (1999). Investigating Japanese learners' beliefs about language learning. System, 27(4), 473-492.

Schulz, R. A. (2001). Cultural differences in student and teacher perceptions concerning the role of grammar instruction and corrective feedback: USA-Colombia. The Modern Language Journal, 85(2), 244-258.

Shah, P. M., Yusof, A., Sulaiman, A. S., Kudus, N. A., Yusof, H. M., \& Latiff, N. A. A. (2009). Comparative analysis of learners' beliefs about ELL. The International Journal of Learning, 16(11), 487-500.

TANAKA, K., \& ELLIS, R. (2003). Study-abroad, language proficiency, and learner beliefs about language learning. JALT Journal, 25(1), 63-85.

TERCANLIOgLu, L. (2005). Pre-service EFL teachers' beliefs about foreign language learning and how they relate to gender. Electronic Journal of Research in Educational Psychology, 3(1), 145-162. Retrieved from http://investigacion-psicopedagogica.org/revista/new/english/ContadorArticulo.php?58

TRUiTT, S. N. (1995). Beliefs about language learning: A study of Korean university students learning beliefs. Texas Papers in Foreign Language Education, 2(1), 1-14. Retrieved from http:// www.eric.ed.gov/PDFS/ED416703.pdf

WENDEN, A. L. (1999). An introduction to metacognitive knowledge and beliefs in language learning: beyond the basics. System, 27(4), 435-441.

YANG, N. D. (1999). The relationship between EFL learners' beliefs and learning strategy use. System, 27(4), 515-535.

\section{Author}

Ladislav Václavík, PhD., Masaryk University Language Centre, e-mail: 20439@mail.muni.cz The author has been teaching at the Masaryk University Language Centre since 2014, he specialises in business English and French for Specific Purposes (academic, medical). As a researcher, he focuses on course design, ICT and blended-learning areas, vocabulary acquisition, plurilingualism, and issues related to creativity and motivation. He also translates novels and short-stories from English, French and Portuguese. 


\section{Attachment}

\section{French through English Questionnaire}

Please answer the questions below. Please note that the scale refers to $\mathbf{1}=$ strongly disagree; 5 = strongly agree unless indicated otherwise.

00 My gender (please circle): M - F

01 English is my native language: YES - NO

\section{PART I}

02 It is important to know English. $1-2-3-4-5$

03 It is necessary to know English: (please check as many as apply)

(a) For career/professional reasons

(b) For social reasons

(c) For communication with foreign entities

(d) Because it is a universal/international language

(e) I disagree. I do not believe that it is necessary to know English.

04 I would like to get to know native speakers of English.

05 I enjoy practising English with the native speakers of English I meet.

06 I feel timid speaking English with other people. $1-2-3-4-5$

07 It is easier to read and write English than to speak and understand it.

08 English is: (1) a very difficult language, (2) a difficult lang., (3) a lang. of medium difficulty, (4) an easy lang., (5) a very easy language.

09 It is important to speak English with excellent pronunciation. $1-2-3-4-5$

10 It is ok to guess if you don't know a word in English. $1-2-3-4-5$

11 It is necessary to know about English-speaking cultures in order to speak English.

12 If beginning students are permitted to make errors in English, it will be difficult for them to speak correctly later on.

13 I would like to work in an English-speaking environment in the future.

14 I have been in the Czech Republic since:

a) Less than three months

b) Three to six months

c) More than six months

15 For an Erasmus student in the Czech Rep., it is important to be able to speak English. $1-2-3-4-5$ 


\section{PART II}

16 The knowledge of English was beneficial in learning French vocabulary. $1-2-3-4-5$

17 The knowledge of English was beneficial in learning French grammar. $1-2-3-4-5$ 18 The knowledge of English was beneficial in learning French pronunciation. 1 - 2 - 3 - 4 - 5

19 When studying French vocabulary on my own, I was aware of the similarities between English and French.

$1-2-3-4-5$

20 When studying French on my own, I used English rather than my mother tongue.

$1-2-3-4-5$

21 When studying French vocabulary on my own, I used mainly translation into my native language. $1-2-3-4-5$

22 How difficult was this part of the French language for you to learn?

$\begin{array}{ll}\text { Vocabulary } & \text { easy } 1-2-3-4-5 \text { hard } \\ \text { Grammar } & \text { easy } 1-2-3-4-5 \text { hard } \\ \text { Listening skill } & \text { easy } 1-2-3-4-5 \text { hard } \\ \text { Writing skill } & \text { easy } 1-2-3-4-5 \text { hard } \\ \text { Speaking skill } & \text { easy } 1-2-3-4-5 \text { hard } \\ \text { Reading skill } & \text { easy } 1-2-3-4-5 \text { hard }\end{array}$

23 Learning a foreign language is mostly a matter of learning a lot of new vocabulary. $1-2-3-4-5$

24 Learning a foreign language is mostly a matter of learning a lot of grammar rules. $1-2-3-4-5$

25 You shouldn't say anything in a foreign language until you can say it correctly. $1-2-3-4-5$

\section{PART III}

26 It is important to know French. $1-2-3-4-5$

27 It is necessary to know French: (a) For career/professional reasons

(please check as many as apply) (b) For social reasons

(c) For communication with foreign entities

(d) Because it is a universal/international language

(e) I disagree. I do not believe that it is necessary to know French.

28 I would like to get to know native speakers of French. $1-2-3-4-5$

29 I enjoy practising French with the native speakers of French I meet. $1-2-3-4-5$

30 I (would) feel timid speaking French with other people. $1-2-3-4-5$ 
31 It is easier to read and write French than to speak and understand it.

$1-2-3-4-5$

32 French is: (1) a very difficult language, (2) a difficult lang., (3) a lang. of medium difficulty,

(4) an easy lang., (5) a very easy language.

$1-2-3-4-5$

33 It is important to speak French with excellent pronunciation.

$1-2-3-4-5$

34 It is ok to guess if you don't know a word in French.

$1-2-3-4-5$

35 It is necessary to know about French-speaking cultures in order to speak French. $1-2-3-4-5$

36 If beginning students are permitted to make errors in French, it will be difficult for them to speak correctly later on.

$1-2-3-4-5$

37 You shouldn't say anything in French until you can say it correctly.

$1-2-3-4-5$

38 I would like to work in a French-speaking environment in the future.

$1-2-3-4-5$

39 For an Erasmus student in the Czech Rep., it is important to be able to speak French.

$1-2-3-4-5$

\section{PART IV}

40 It was hard for me to study French using English.

$1-2-3-4-5$

41 I would prefer if the teacher spoke only French.

$1-2-3-4-5$

42 In class, I used to translate words from English into my native language. $1-2-3-4-5$

43 In general, studying foreign languages using English is useful. $\quad 1-2-3-4-5$

44 Learning French is mostly a matter of translating from English into French. $1-2-3-4-5$

45 In class, I had problems understanding the teacher's English.

$1-2-3-4-5$

46 When learning vocabulary, I used a French-only dictionary.

$1-2-3-4-5$ 